\title{
Type D personality, anxiety sensitivity, social anxiety, and disability in patients with acne: a cross-sectional controlled study
}

\author{
Betul Sereflican ${ }^{1}$, Taha Can Tuman², Bengü Altunay Tuman'1 , Ali Haydar Parlak ${ }^{1}$
}

'Department of Dermatology, Medical Faculty, Abant Izzet Baysal University, Bolu, Turkey ${ }^{2}$ Psychiatry Clinic, Bolu Izzet Baysal Mental Health Hospital, Bolu, Turkey

Adv Dermatol Allergol 2019; XXXVI (1): 51-57 DOI: https://doi.org/10.5114/ada.2019.82824

\begin{abstract}
Introduction: Acne has long been associated with many psychiatric comorbidities.

Aim: To determine anxiety and depression levels, social phobia frequency, social anxiety level, subjective stress perception, anxiety sensitivity, disability, and the frequency of type $D$ personality in patients with acne.

Material and methods: In total, 61 patients with acne aged > 16 years and 61 age, gender, and educationally matched healthy volunteers were included in the study. The patients and healthy controls were evaluated using the Diagnostic and Statistical Manual of Mental Disorders (DSM)-5 criteria for social anxiety disorder and completed the Liebowitz Social Anxiety Scale, Sheehan Disability Scale, Anxiety Sensitivity Index, Hospital Anxiety and Depression Scale, Perceived Stress Scale (PSS), and Type D Scale-14.

Results: Depression, anxiety, social anxiety, self-reported stress, anxiety sensitivity, and disability levels were significantly higher in patients with acne than in healthy controls $(p<0.05)$. Type $\mathrm{D}$ personality was more prevalent in patients with acne than in healthy controls ( $49 \%$ vs. $18 \%, p<0.001)$.

Conclusions: To our knowledge, this study is the first reported in which type D personality and anxiety sensitivity, as well as social anxiety disorder according to the DSM-5 criteria, was evaluated in patients with acne compared with healthy controls. This study shows that patients with acne have higher levels of depression, anxiety, social anxiety, self-reported stress, anxiety sensitivity, and disability, and a greater prevalence of type $D$ personality, than healthy controls. Psychiatric evaluation of patients with acne may aid the detection of mental disorders.
\end{abstract}

Key words: acne, type D personality, anxiety sensitivity, social anxiety, DSM-5, disability.

\section{Introduction}

The skin is the largest organ of the human body. Healthy skin plays a considerable role in a person's physical, social, and psychological fitness [1]. Physical appearance and beauty are much more important to many people in the $21^{\text {st }}$ century than in previous generations [2]. Consequently, skin diseases with cosmetic deterioration can lead to increased depression, anxiety, and feelings of stigmatization [1].

Acne vulgaris is a common skin disease that usually occurs on the face [2]. Its onset in adolescence or young adulthood and predominant facial involvement may provoke psychological effects because the appearance of the skin is important for social interplay and self-esteem in this age group [3, 4]. Acne has been suggested to have many psychological effects, such as low self-esteem, low self-confidence, perceived social rejection, social avoidance, anxiety, depression, and even suicidal ideation [4-8].

Social anxiety disorder (SAD; also known as social phobia) is the most common type of anxiety disorder worldwide [9]. Persons with SAD fear being humiliated in public; they are withdrawn in unfamiliar social environments and avoid social activities, such as speaking in public [10]. With the publication of the Diagnostic and Statistical Manual of Mental Disorders (DSM)-5 [11], the diagnostic criteria for SAD have undergone some alterations. To our knowledge, the literature contains no study of patients with acne that has employed these new criteria.

A type D, or "distressed", personality is characterized by a combination of negative affectivity and social in-

Address for correspondence: Betul Sereflican MD, Assist. Prof., Department of Dermatology, Medical Faculty, Abant Izzet Baysal University, 14280 Golkoy, Bolu, Turkey, phone: +90 374 2534656, fax: +90 374 2534615, e-mail: ozbetul@yahoo.com Received: 12.09.2017, accepted: 13.11.2017. 
hibition [12]. Patients with type D personality perceive more anxiety, depression, and anger, and restrict selfexpression to avoid disapproval [13]. The Type D Scale-14 (DS14) was developed to detect negative affectivity, social inhibition, and type $D$ personality in a reliable and standardized manner [14].

Anxiety sensitivity (AS) is defined as fear of anxiety symptoms that results from beliefs about the detrimental physical, social, and/or psychological outcomes of such symptoms [15]. A new version of the Anxiety Sensitivity In$\operatorname{dex}(\mathrm{ASI})$, the ASI-3, which measures AS, consists of three subscales: physical, cognitive, and social concerns [16]. The AS has been reported as a risk factor for anxiety disorders, major depressive disorder, and suicidal ideation [17].

To our knowledge, no reported study has examined type D personality and AS in patients with acne compared with healthy controls.

\section{Aim}

The aim of this study was to evaluate anxiety and depression levels, subjective stress perception, social anxiety and avoidance, AS, and disability, and the frequency of type $D$ personality in patients with acne.

\section{Material and methods}

This study included 61 dermatology clinic outpatients with acne vulgaris aged 16-26 years and 61 age, gender, and educationally matched healthy volunteers without acne or any other skin disease. The local ethics committee approved this study. Informed consent to participation was obtained from each subject. Individuals with systemic diseases, schizophrenia, mental retardation, autism, dementia, bipolar disorder, epilepsy, use of antiepileptic drugs, age < 16 years, use of systemic therapy for acne, or any other skin disease were excluded.

Data on participants' demographic characteristics, smoking history, consumption of alcohol, disease duration, family history, medication history, and history of mental illness were collected. Acne severity was evaluated using the Global Acne Grading System [18]. Following dermatological evaluation, the following questionnaires were completed during single interviews: the Liebowitz Social Anxiety Scale (LSAS), Sheehan Disability Scale (SDS), ASI, Hospital Anxiety and Depression Scale (HADS), Perceived Stress Scale (PSS), and DS14. Participants were also evaluated using the DSM-5 criteria for SAD.

\section{Liebowitz Social Anxiety Scale (LSAS)}

The LSAS comprises two subscales that assess social avoidance and social fear. It has 24 items measuring social interaction and performance in social environments [19]. Soykan et al. [20] demonstrated the validity and reliability of the Turkish version of the LSAS.

\section{Sheehan Disability Scale (SDS)}

The SDS is a three-item measure used to determine functional disability in work, social, and family life [21].

\section{Anxiety Sensitivity Index-3 (ASI-3)}

The ASI measures AS, or fear of anxiety-related emotions [22]. A new version of the ASI, the ASI-3, consists of 18 items [16]. It evaluates the three most cantilevered AS domains: social, cognitive, and physical [23]. Mantar et al. [24] demonstrated the validity and reliability of the Turkish version of the ASI-3.

\section{Hospital Anxiety and Depression Scale (HADS)}

The HADS is a self-administered scale that consists of 14 items used to determine depression and anxiety levels [25]. Aydemir et al. [26] demonstrated the validity and reliability of the Turkish version of the HADS.

\section{Perceived Stress Scale (PSS)}

The PSS was developed as a 14-item scale used to assess an individual's psychological distress. The individual answers questions about his/her feelings concerning events that occurred over the previous month [27]. Eskin et al. [28] demonstrated the validity and reliability of the Turkish version of the PSS. The 14 items cluster into two subscales: insufficient self-efficacy perception and stress/discomfort perception.

\section{Type D Scale-14}

The DS14 measures distressed personality. This type of personality is characterized mainly by two attitudes: negative affectivity and social inhibition [29]. Alçelik et al. [30] demonstrated the validity and reliability of the Turkish version of the DS14 with a preliminary study.

\section{DSM-5 Social Anxiety Disorder (SAD)}

This assessment evaluates social anxiety or social phobia according to the DSM-5 criteria, and was published in 2013 [11].

\section{Statistical analysis}

Statistical analyses were performed using the SPSS software (ver. 17; SPSS Inc., Chicago, IL, USA). Data are shown as means \pm standard deviations for continuous variables, medians (ranges) for ordinal variables, and frequencies with percentages for categorical variables. The distribution of the numerical data was checked by the Kolmogorov-Smirnov test and visual items (histogram curves). Categorical variables were compared among groups using the $\chi^{2}$ test or Fisher's exact test. Comparisons among groups were performed using independentsample $t$ tests and Mann-Whitney $U$ tests for normally and non-normally distributed data, respectively. Correlations were evaluated by Spearman's correlation test. 
$P$-values $<0.05$ were considered to indicate statistical significance.

\section{Results}

The study included 61 patients with acne $(54 \mathrm{fe}-$ males, 7 males) and 61 healthy individuals (51 females, 10 males). The median ages in the patient and control groups were 20 (range: 16-26) years and 20 (range: 16-28) years, respectively. The patients with acne and healthy individuals were matched according to age and gender ( $p=0.433$ and $p=0.608$, respectively). All partici- pants had graduated from university or high school; educational status did not differ between patients with acne and controls ( $p=0.487)$. The proportions of married persons were lesser than those of single individuals in both groups, with no significant difference in marital status between groups $(p=1)$. Baseline demographic and clinical data (male/female ratio, marital status, educational status, smoking history, consumption of alcohol, disease duration, disease severity) of participants enrolled in this study are shown in Table 1.

The LSAS, SDS, PSS, and HADS total and subscale scores were significantly higher among patients with

Table 1. Demographic and clinical information of the patient and control group

\begin{tabular}{|c|c|c|c|}
\hline Parameter & $\begin{array}{c}\text { Acne patients }(n=61) \\
\text { Mean } \pm \text { SD, median (range) } \\
\text { or } n(\%)\end{array}$ & $\begin{array}{l}\text { Control subjects }(n=61) \\
\text { Mean } \pm \text { SD, median (range) } \\
\text { or } n(\%)\end{array}$ & $P$-value \\
\hline Sex, male & $7(11.5)$ & $10(16.4)$ & 0.433 \\
\hline Marital status, married & $2(3)$ & $3(5)$ & 1 \\
\hline Educational status, university & $51(84)$ & $48(79)$ & 0.487 \\
\hline Smoking history, present & $7(12)$ & $13(21)$ & 0.142 \\
\hline Consumption of alcohol, present & $3(5)$ & $9(15)$ & 0.068 \\
\hline Disease duration [years] & $4(1-19)$ & - & \\
\hline Family history of acne, present & $26(43)$ & - & \\
\hline History of mental illness, present & $4(7)$ & 0 & 0.119 \\
\hline Family history of mental illness, present & $2(3)$ & $4(7)$ & 0.680 \\
\hline Previous Psychiatric Treatment, present & $5(8)$ & 0 & 0.057 \\
\hline Acne severity score & $12.98 \pm 6.26$ & & \\
\hline
\end{tabular}

Table 2. Comparison of LSAS, HADS, SDS, ASI-3, PSS scores between acne and control group

\begin{tabular}{llccc}
\hline Variable & & Acne $(n=61)$ & Control $(n=61)$ & $P$-value \\
\hline \multirow{2}{*}{ LSAS } & Fear & $43(30-75)$ & $31(26-63)$ & $<0.001$ \\
\cline { 2 - 5 } & Avoidance & $38(27-73)$ & $31(26-63)$ & $<0.001$ \\
\cline { 2 - 5 } & Total score & $82(58-145)$ & $62(52-126)$ & $<0.001$ \\
\hline \multirow{2}{*}{ HADS } & Anxiety & $8(0-17)$ & $4(0-10)$ & $<0.001$ \\
\cline { 2 - 5 } & Depression & $5(0-15)$ & $3(0-9)$ & $<0.001$ \\
\hline \multirow{2}{*}{ ASI-3 } & Work & $1(0-2)$ & 0 & $<0.001$ \\
\cline { 2 - 5 } & Social & $1(0-3)$ & 0 & $<0.001$ \\
\cline { 2 - 5 } & Family & $0(0-3)$ & $2(0-14)$ & 0.001 \\
\cline { 2 - 5 } & Cognitive & $5(0-23)$ & $4(0-19)$ & 0.262 \\
\cline { 2 - 5 } & Social & $4(0-23)$ & $5(0-16)$ & 0.099 \\
\cline { 2 - 5 } & Total score & $6(0-20)$ & $12(3-29)$ & 0.017 \\
\hline \multirow{2}{*}{ PSS } & Insufficient self-efficacy & $15(3-55)$ & $4(0-14)$ & $<0.001$ \\
\cline { 2 - 5 } & Stress/discomfort & $12(5-22)$ & $5(0-13)$ & $<0.001$ \\
\cline { 2 - 5 } & Total score & $16(3-28)$ & $10(0-24)$ & $<0.001$ \\
\hline
\end{tabular}

LSAS - Liebowitz Social Anxiety Scale, HADS - Hospital Anxiety and Depression Scale, SDS - Sheehan Disability Scale, ASI-3 - Anxiety Sensitivity Index, PSS - Perceived Stress Scale. 
Table 3. Correlations between acne severity and scale scores

\begin{tabular}{lll}
\hline \multicolumn{2}{c}{ Scale scores } & $\begin{array}{c}\text { Acne severity } \\
r(p \text {-value })\end{array}$ \\
\hline \multirow{2}{*}{ LSAS } & Fear & $0.146(0.262)$ \\
\cline { 2 - 3 } & Avoidance & $0.135(0.301)$ \\
\cline { 2 - 3 } & Total score & $0.115(0.378)$ \\
\hline HADS & Anxiety & $-0.108(0.408)$ \\
\cline { 2 - 3 } & Depression & $0.056(0.666)$ \\
\hline SDS & Work & $-0.027(0.839)$ \\
\cline { 2 - 3 } & Social & $0.062(0.633)$ \\
\cline { 2 - 3 } & Family & $0.064(0.623)$ \\
\hline \multirow{2}{*}{ ASI-3 } & Physical & $-0.097(0.457)$ \\
\cline { 2 - 3 } & Cognitive & $-0.131(0.315)$ \\
\cline { 2 - 3 } & Social & $-0.121(0.354)$ \\
\cline { 2 - 3 } & Total score & $-0.122(0.349)$ \\
\hline PSS & Insufficient & $-0.163(0.209)$ \\
\cline { 2 - 3 } & self-efficacy & $-0.265(0.039)$ \\
\cline { 2 - 3 } & Stress/discomfort & $-0.244(0.058)$ \\
\cline { 2 - 3 } & Total score & \\
\hline
\end{tabular}

LSAS - Liebowitz Social Anxiety Scale, HADS - Hospital Anxiety and Depres sion Scale, SDS - Sheehan Disability Scale, ASI-3 - Anxiety Sensitivity Index PSS - Perceived Stress Scale. acne than among healthy subjects (Table 2). ASI-3 total and physical domain scores were significantly higher in the patient group, but ASI-3 cognitive and social subscale scores did not differ between the patient and control groups ( $p=0.017, p=0.001, p=0.262$, and $p=0.099$, respectively).

About half ( $n=30,49 \%)$ of patients with acne had type D personality. This rate was significantly lower in healthy subjects $(n=11,18 \% ; p<0.001)$.

Based on the DSM-5 criteria, $66 \%(n=40)$ of patients with acne had SAD. This proportion was significantly lower in the control group $(n=14,23 \% ; p<0.001)$.

Acne severity was not correlated with the LSAS, SDS, HADS, or ASI-3 score (Table 3). We found a weak negative correlation between acne severity and the PSS stress-discomfort perception subscale score $(r=-0.265$, $p=0.039$ ).

In the acne group, the duration of disease was correlated negatively with the ASI-3 cognitive score ( $r=$ $-0.272, p=0.034)$ and the PSS insufficient self-efficacy score $(r=-0.292, p=0.022)$.

Acne severity did not differ between those with and those without type D personality ( $13.6 \pm 6.2$ vs. $12.4 \pm 6.3$; $p=0.454)$ or between patients with and without SAD (13.4 \pm 6.5 vs. $12.3 \pm 6.0 ; p=0.533)$.

Table 4. The relationship of the LSAS, HADS, SDS, ASI-3 and PSS scores with type D personality in patients with acne

\begin{tabular}{|c|c|c|c|c|}
\hline \multicolumn{2}{|c|}{ Variable } & $\begin{array}{l}\text { Acne patients without type } \mathrm{D} \\
\text { personality }(n=31)\end{array}$ & $\begin{array}{c}\text { Acne patients with type } \mathrm{D} \\
\text { personality }(n=30)\end{array}$ & $P$-value \\
\hline \multicolumn{2}{|c|}{ Acne severity } & $12.4 \pm 6.3$ & $13.6 \pm 6.2$ & 0.454 \\
\hline \multirow[t]{3}{*}{ LSAS } & Fear & $40(30-63)$ & $46(32-75)$ & 0.025 \\
\hline & Avoidance & $37(28-62)$ & $44.5(27-73)$ & 0.067 \\
\hline & Total Score & $77(58-124)$ & $91(61-145)$ & 0.022 \\
\hline \multirow[t]{2}{*}{ HADS } & Anxiety & $6(0-11)$ & $10(4-17)$ & $<0.001$ \\
\hline & Depression & $3(0-8)$ & $9(1-15)$ & $<0.001$ \\
\hline \multirow[t]{3}{*}{ SDS } & Work & $0(0-2)$ & $1(0-2)$ & 0.019 \\
\hline & Social & $1(0-3)$ & $1(0-3)$ & 0.102 \\
\hline & Family & $0(0-3)$ & $0(0-3)$ & 0.516 \\
\hline \multirow[t]{4}{*}{ ASI-3 } & Physical & $4(0-17)$ & $5.5(0-23)$ & 0.188 \\
\hline & Cognitive & $3(0-21)$ & $7(1-23)$ & 0.020 \\
\hline & Social & $4(0-20)$ & $7.5(0-20)$ & 0.018 \\
\hline & Total Score & $12(3-55)$ & $18(3-49)$ & 0.014 \\
\hline \multirow[t]{3}{*}{ PSS } & Insufficient self-efficacy & $10(5-19)$ & $15(7-22)$ & $<0.001$ \\
\hline & Stress/discomfort & $14.6 \pm 5.5$ & $17.6 \pm 5.1$ & 0.035 \\
\hline & Total score & $25.2 \pm 8.3$ & $32.0 \pm 7.4$ & 0.001 \\
\hline
\end{tabular}

LSAS - Liebowitz Social Anxiety Scale, HADS - Hospital Anxiety and Depression Scale, SDS - Sheehan Disability Scale, ASI-3 - Anxiety Sensitivity Index, PSS - Perceived Stress Scale. 
Many scale scores were significantly higher in individuals with than in those without type D personality (Table 4).

The LSAS fear subscale and total scores were significantly higher in subjects with SAD (LSAS fear subscale: 45.5 (30-75) vs. 38 (30-55), $p=0.001$; LSAS total, 86 (60-145) vs. 72 (58-112), $p=0.023)$. Other scale scores were similar in subjects with and without SAD $(p>0.05)$.

In the multivariate regression analyses, there was a significant positive correlation between PSS total score and the presence of acne $\left(p<0.001, \beta=0.881, R^{2}=0.679\right)$, but no such relationships were observed between acne and other scales. Also, a positive linear relationship was found between the presence of type D personality and the HADS anxiety score and the HADS depression score when evaluating those with and those without type $D$ personality in acne patients ( $p=0.01, \beta=0.391, R^{2}=0.457 ; p<$ $0.001, \beta=0.517, R^{2}=0.457$, respectively), however no such relationships were observed with other scales.

\section{Discussion}

Acne is a multifactorial chronic inflammatory disease. It is the leading reason for visits to dermatologists. It seriously influences affected individuals' well-being [31, 32]. The psychological effects of the disease have often been undervalued [33].

Social phobia or SAD is a frequent accompanying disorder in patients with acne [34, 35]. According to the new DSM-5 criteria, a diagnosis of SAD requires the persistence of fear, anxiety, and avoidance for at least 6 months; fear or anxiety is disproportionate to the situation to be avoided in the social environment and to the social cultural context. The phrase "the person knows that his fear is excessive and meaningless", present in the DSM-4, has been removed from the criteria in the DSM-5. Also, the DSM-5 criteria enable the diagnosis of $S A D$ in the presence of another general medical condition when the social fear, anxiety, or avoidance is not connected to the medical disorder or "is excessive", unlike the DSM-4 criteria [36]. We found a significantly greater prevalence of SAD, defined using the DSM- 5 criteria, in patients with acne than in controls. We found no report in the literature in which social phobia in patients with acne was evaluated in accordance with the DSM-5 classification. In our patient group, LSAS anxiety and total scale scores were significantly higher in patients with social phobia than in those without social phobia, as expected. Bez et al. [35] found that the frequency of social phobia was higher in patients with acne than in healthy controls and that all subscale scores and the total LSAS score were significantly higher in patients with acne with social phobia than in those without social phobia. However, they evaluated social phobia using the modified DSM-4 criteria. In our study, LSAS total and subscale scores differed significantly between the patient and healthy control groups. Similar to our results, Öztürk et al. [8], Salman et al. [37] and Yolaç Yarpuz et al. [38] reported higher LSAS total and subscale scores; Bez et al. [35] demonstrated that LSAS avoidance scores were higher among patients with acne than among controls.

In our study, HADS scores were significantly higher in the patient group than in the control group. Consistent with our results, several studies using HADS scores have indicated that anxiety and depression are more common in patients with acne [8, 37-40]. Golchai et al. [41] found a significant elevation in the HADS anxiety score, but not the HADS depression score. In contrast to our results and those of several studies referred to above, Aktan et al. [42] found no significant difference in HADS scores between adolescents with and without acne.

In our study, SDS scores for the work, family, and social life items were significantly higher in the patient group. Bez et al. [35] found that SDS scores only for the work and family life items were significantly higher in patients with acne than in healthy controls; furthermore, disability levels were higher among patients with than among those without social phobia. In contrast, the presence of social phobia did not affect disability in our patient group.

Self-reported stress levels were significantly higher in our patient group than in controls. A few studies in the literature have investigated the perceived stress levels of patients with acne, but they have limitations, including the absence of a healthy control group or information about PSS subscales. In the study conducted by Alsamarai et al. [43], mean PSS scores were significantly higher in patients with acne than in the normal population. In studies involving patient groups but no healthy control group and evaluation using the PSS, Yosipovitch et al. [44] showed a significant association between stress and the severity of acne papulopustulosa, and Chiu et al. [45] showed a significant positive correlation between acne severity and stress level. In contrast, we found a weak negative correlation between acne severity and PSS total and stress-discomfort perception subscale scores.

Elevated AS has been reported to be associated with various anxiety disorders [46]. A high degree of AS may amplify anxiety by prompting progression to panic attacks or agoraphobic reactions [47]. In our study, total AS and AS related to the physical consequences of anxiety were significantly greater in patients with acne than in healthy controls. One study in the literature evaluated the severity of AS among patients with psychodermatological (e.g., rosacea, psoriasis, acne, eczema, atopic dermatitis, alopecia) and non-psychodermatological (e.g., skin cancer, skin damage, warts, keloids, fungal infection) disorders. In that study, patients with psychodermatological conditions reported significantly higher AS than did patients with non-psychodermatological conditions [48]. Although patients with acne were included in the psychodermatological disorders group, this group was not homogeneous and the study did not involve evalua- 
tion of a healthy control group. Thus, to our knowledge, this study is the first reported in which AS was compared between patients with acne and a healthy control group. The AS-related physical concerns have been reported to be associated with panic disorder, agoraphobia, and post-traumatic stress disorder [17]. As the AS total and physical subscale scores were significantly higher in patients with acne in our study, we suggest that patients with acne may show a tendency to develop these conditions.

Psychological factors and personality traits, as well as biological characteristics such as high blood pressure and increased inflammation, are known to play roles in the progression of cardiovascular diseases. Type $D$ personality has been reported to be a risk factor for cardiac events [49]. Adverse effects of type D personality, such as increased risks of poor health-related quality of life, depressive symptoms, and anxiety, also have been observed in patients with cardiovascular disorders [13]. Our results showed a greater prevalence of type $D$ personality among patients with acne than among healthy controls. We found no study in the literature examining any association of type $D$ personality with acne, but a few studies have assessed type D personality in patients with psoriasis; in one study, type D personality was more prevalent in patients with psoriasis than in healthy volunteers, and in another study, type D personality was a significant predictor of perceived stigmatization [50, 51]. In our study, individuals with acne and type D personality demonstrated significant increases in signs of anxiety, depression, SAD, perceived stress, AS, and disability at work compared with patients with acne without type $D$ personality. According to these results, we suggest that psychiatric comorbidities are more prominent in subjects with type D personality and acne, who already have mental health disorders, than in control subjects.

In our study, disease severity was not correlated with any psychiatric scale score except the PSS stress-discomfort perception subscale score. This result suggests that psychological disturbances occur independently of acne severity; widespread and sparse acne lesions have similar effects on patient psychology.

Our study has some limitations, such as its crosssectional single-center design. Also, the greater observed frequencies of psychiatric comorbidities may reflect the selection of outpatients from a clinic, who might already have higher grades of negative emotions than do those not consulting a dermatologist. Additionally, SDS has not been formally validated in Turkish population. These results should be confirmed by further multicenter studies with larger numbers of patients.

\section{Conclusions}

Our study demonstrated that patients with acne have tendencies toward depression, anxiety, SAD, self-reported stress, AS, disability, and type D personality. Today, personality traits and psychiatric disorders are known to be noteworthy in disease pathogenesis and progression, beyond organic causes; thus, psychiatric evaluation along with dermatological assessment is a valuable approach in outpatient clinics. Psychiatric screening may result in early diagnosis and treatment to prevent psychiatric comorbidities; in this way, we can assess all aspects of acne and achieve more successful treatment outcomes.

\section{Acknowledgments}

The study was conducted at Abant Izzet Baysal University, Medical Faculty, Dermatology Department. The work can be attributed to the Dermatology Department.

\section{Conflict of interest}

The authors declare no conflict of interest.

\section{References}

1. Tomas-Aragones L, Marron SE. Body image and body dysmorphic concerns. Acta Derm Venereol 2016; 96: 47-50.

2. Revol O, Milliez N, Gerard D. Psychological impact of acne on $21^{\text {st }}$-century adolescents: decoding for better care. $\mathrm{Br}$ J Dermatol 2015; 172 Suppl 1: 52-8.

3. Hazarika N, Archana M. The psychosocial impact of acne vulgaris. Indian J Dermatol 2016; 61: 515-20.

4. Dalgard F, Gieler U, Holm JO, et al. Self-esteem and body satisfaction among late adolescents with acne: results from a population survey. J Am Acad Dermatol 2008; 59: 746-51.

5. Henkel V, Moehrenschlager M, Hegerl U, et al. Screening for depression in adult acne vulgaris patients: tools for the dermatologist. J Cosmet Dermatol 2002; 1: 202-7.

6. Dalgard FJ, Gieler U, Tomas-Aragones L, et al. The psychological burden of skin diseases: a cross-sectional multicenter study among dermatological out patients in 13 European countries. J Invest Dermatol 2015; 135: 984-91.

7. Halvorsen JA, Stern RS, Dalgard F, et al. Suicidal ideation, mental health problems, and social impairment are increased in adolescents with acne: a population based study. J Invest Dermatol 2011; 131: 363-70.

8. Öztürk A, Deveci E, Bağcığlu E, et al. Anxiety, depression, social phobia, and quality of life in Turkish patients with acne and their relationships with the severity of acne. Turk J Med Sci 2013; 43: 660-6.

9. Mekuria K, Mulat H, Derajew H, et al. High magnitude of social anxiety disorder in school adolescents. Psychiatry J 2017; 2017: 5643136.

10. Stein MB, Stein DJ. Social anxiety disorder. Lancet 2008; 371 : 1115-25.

11. American Psychiatric Association. Diagnostic and Statistical Manual for Mental Disorders. $5^{\text {th }}$ edition (DSM-5). Arlington, VA: American Psychiatric Publishing; 2013.

12. Denollet J. Type D personality. A potential risk factor refined. J Psychosom Res 2000; 49: 255-66.

13. Denollet J, Kupper N. Type-D personality, depression, and cardiac prognosis: cortisol dysregulation as a mediating mechanism. J Psychosom Res 2007; 62: 607-9. 
14. Denollet J. DS14: standard assessment of negative affectivity, social inhibition, and type D personality. Psychosom Med 2005; 67: 89-97.

15. Rector NA, Szacun-Shimizu K, Leybman M. Anxiety sensitivity within the anxiety disorders: disorder-specific sensitivities and depression comorbidity. Behav Res Ther 2007; 45: 1967-75.

16. Olthuis JV, Watt MC, Stewart SH. Anxiety Sensitivity Index (ASI-3) subscales predict unique variance in anxiety and depressive symptoms. J Anxiety Disord 2014; 28: 115-24.

17. Allan NP, Capron DW, Raines AM, Schmidt NB. Unique relations among anxiety sensitivity factors and anxiety, depression, and suicidal ideation. J Anxiety Disord 2014; 28 : 266-75.

18. Doshi A, Zaheer A, Stiller MJ. A comparison of current acne grading systems and proposal of a novel system. Int J Dermatol 1997; 36: 416-8.

19. Tyrała K, Seweryn M, Bonk M, et al. Evaluation of the utility of Liebowitz Social Anxiety Scale and Barratt Impulsiveness Scale in the diagnosis of social anxiety, impulsivity and depression. Psychiatr Danub 2015; 27 Suppl 1: S223-6.

20. Soykan C, Ozguven HD, Gencoz T. Liebowitz Social Anxiety Scale: the Turkish version. Psychol Rep 2003; 93: 1059-69.

21. Sheehan KH, Sheehan DV. Assessing treatment effects in clinical trials with the discan metric of the Sheehan Disability Scale. Int Clin Psychopharmacol 2008; 23: 70-83.

22. McNally RJ. Anxiety sensitivity and panic disorder. Biol Psychiatry 2002; 52: 938-46.

23. Rifkin LS, Beard C, Hsu KJ, et al. Psychometric properties of the anxiety sensitivity index 3 in an acute and heterogeneous treatment sample. J Anxiety Disord 2015; 36: 99-102.

24. Mantar A, Yemez B, Alkın T. The validity and reliability of Turkish version of anxiety sensitivity index-3. Turk Psikiyatri Derg 2010; 21: 225-34.

25. Zigmond AS, Snaith RP. The hospital anxiety and depression scale. Acta Psychiatr Scand 1983; 67: 361-70.

26. Aydemir O, Guvenir T, Kuey L, Kultur S. Hastane anksiyete ve depresyon olçegi Turkce formunun gecerlilik ve guvenilirligi. Turk Psikiyatri Derg 1997; 8: 280-7.

27. Nielsen MG, Ørnbøl E, Vestergaard M, et al. The construct validity of the Perceived Stress Scale. J Psychosom Res 2016; 84: 22-30.

28. Eskin M, Harlak H, Demirkıran F, Dereboy Ç. Algılanan Stres Ölçeğinin Türkçeye Uyarlanması: Güvenirlik ve Geçerlik Analizi. Yeni Symposium 2013; 51: 132-140.

29. Straat JH, van der Ark LA, Sijtsma K. Multi-method analysis of the internal structure of the Type D Scale-14 (DS14). J Psychosom Res 2012; 72: 258-65.

30. Alçelik A, Yıldırım O, Canan F, et al. A preliminary psychometric evaluation of the type $D$ personality construct in Turkish hemodialysis patients. J Mood Disord 2012; 2: 1-5.

31. Bergler-Czop B, Brzezińska-Wcisło L. Dermatological problems of the puberty. Postep Dermatol Alergol 2013; 30: 178-87.

32. Pawin $\mathrm{H}$, Chivot $\mathrm{M}$, Beylot $\mathrm{C}$, et al. Living with acne. A study of adolescents' personal experiences. Dermatology 2007; 215: 308-14.

33. Gieler U, Gieler T, Kupfer JP. Acne and quality of life - impact and management. J Eur Acad Dermatol Venereol 2015; 29 Suppl 4: 12-4.

34. Uzun O, Başoğlu C, Akar A, et al. Body dysmorphic disorder in patients with acne. Compr Psychiatry 2003; 44: 415-9.
35. Bez Y, Yesilova Y, Kaya MC, Sir A. High social phobia frequency and related disability in patients with acne vulgaris. Eur J Dermatol 2011; 21: 756-60.

36. Heimberg RG, Hofmann SG, Liebowitz MR, et al. Social anxiety disorder in DSM-5. Depress Anxiety 2014; 31: 472-9.

37. Salman A, Kurt E, Topcuoglu V, Demircay Z. Social anxiety and quality of life in vitiligo and acne patients with facial involvement: a cross-sectional controlled study. Am J Clin Dermatol 2016; 17: 305-11.

38. Yolaç Yarpuz A, Demirci Saadet E, Erdi Sanli H, Devrimci Ozgüven $\mathrm{H}$. Social anxiety level in acne vulgaris patients and its relationship to clinical variables. Turk Psikiyatri Derg 2008; 19: 29-37.

39. Awad SM, Morsy H, Sayed AA, et al. Oxidative stress and psychiatric morbidity in patients with facial acne. J Cosmet Dermatol 2018; 17: 203-8.

40. Yazici K, Baz K, Yazici AE, et al. Disease-specific quality of life is associated with anxiety and depression in patients with acne. J Eur Acad Dermatol Venereol 2004; 18: 435-9.

41. Golchai J, Khani SH, Heidarzadeh A, et al. Comparison of anxiety and depression in patients with acne vulgaris and healthy individuals. Indian J Dermatol 2010; 55: 352-4.

42. Aktan S, Özmen E, Sanli B. Anxiety, depression, and nature of acne vulgaris in adolescents. Int I Dermatol 2000; 39: 354-7.

43. Alsamarai AM, Aljubori AM. Association between stress and skin disease. Middle East J Intern Med 2010; 3: 12-9.

44. Yosipovitch G, Tang M, Dawn AG, et al. Study of psychological stress, sebum production and acne vulgaris in adolescents. Acta Derm Venereol 2007; 87: 135-9.

45. Chiu A, Chon SY, Kimball AB. The response of skin disease to stress: changes in the severity of acne vulgaris as affected by examination stress. Arch Dermatol 2003; 139: 897-900.

46. Lebowitz ER, Shic F, Campbell D, et al. Anxiety sensitivity moderates behavioral avoidance in anxious youth. Behav Res Ther 2015; 74: 11-7.

47. Bravo IM, Silverman WK. Anxiety sensitivity, anxiety, and depression in older patients and their relation to hypochondriacal concerns and medical illnesses. Aging Ment Health 2001; 5: 349-57.

48. Dixon LJ, Lee AA, Viana AG, et al. Anxiety sensitivity in dermatological patients. Psychosomatics 2016; 57: 498-504.

49. Kupper N, Denollet J. Type D personality as a prognostic factor in heart disease: assessment and mediating mechanisms. J Pers Assess 2007; 89: 265-76.

50. Molina-Leyva A, Caparros-delMoral I, Ruiz-Carrascosa JC, et al. Elevated prevalence of type $D$ (distressed) personality in moderate to severe psoriasis is associated with mood status and quality of life impairment: a comparative pilot study. J Eur Acad Dermatol Venereol 2015; 29: 1710-7.

51. Van Beugen S, van Middendorp H, Ferwerda M, et al. Predictors of perceived stigmatization in patients with psoriasis. Br J Dermatol 2017; 176: 687-94. 